\title{
Article \\ Compact Model of a Screen under Fan-Induced Swirl Conditions Using a Porous Media Approach
}

\author{
Asier Bengoechea ${ }^{1,2}$, Raúl Antón ${ }^{2} \mathbb{D}$, Alejandro Rivas ${ }^{2}$, Gorka S. Larraona ${ }^{2}$ and Juan Carlos Ramos ${ }^{2, *}$ D \\ 1 Sarralle Steel Melting Plant, Engineering Department, Orendaundi Kalea 7, 20730 Azpeitia, Spain; \\ abengoetxea@sarralle.com \\ 2 Thermal and Fluids Engineering Division, Mechanical Engineering and Materials Department, \\ TECNUN-School of Engineering, University of Navarra, Paseo de Manuel de Lardizábal 13, \\ 20018 San Sebastián, Spain; ranton@tecnun.es (R.A.); arivas@tecnun.es (A.R.); gsanchez@tecnun.es (G.S.L.) \\ * Correspondence: jcramos@tecnun.es
}

check for updates

Citation: Bengoechea, A.; Antón, R.; Rivas, A.; Larraona, G.S.; Ramos, J.C. Compact Model of a Screen under Fan-Induced Swirl Conditions Using a Porous Media Approach. Appl. Sci. 2021, 11, 1999. https://doi.org/ 10.3390/app11051999

Academic Editor: Jesús María Blanco

Received: 22 January 2021

Accepted: 20 February 2021

Published: 24 February 2021

Publisher's Note: MDPI stays neutral with regard to jurisdictional claims in published maps and institutional affiliations.

Copyright: (c) 2021 by the authors. Licensee MDPI, Basel, Switzerland. This article is an open access article distributed under the terms and conditions of the Creative Commons Attribution (CC BY) license (https:// creativecommons.org/licenses/by/ $4.0 /)$.

\begin{abstract}
A perforated plate in an electronic device is typically placed downstream of an axial fan (push cooling) in order to avoid electromagnetic interferences. Because of the swirling component in the flow approaching the screen, determining how the screen affects the flow pattern downstream of the screen is a challenge. It is important to understand this interaction, as the correct location of the electronic components will depend on the flow pattern (the components that dissipate more heat will be located where the maximum magnitude of the velocity is located). This work aims to present an approach of the flow pattern via a compact model based on three directional pressure loss coefficients. The values for the pressure loss coefficients are obtained through different correlations depending on the flow and geometric characteristics for the case that is being modeled. These correlations are obtained through an iterative process that compares different flow patterns obtained through different modeling strategies: the compact one that is presented in this paper and another detailed one, which was validated in previous works. Results show that if this compact model is used, an approximation of the flow pattern could be obtained with a huge decrease in the amount of time invested.
\end{abstract}

Keywords: flow pattern; swirl flow; computational fluid dynamics (CFD); perforated plate; pressure loss coefficients; compact model

\section{Introduction}

Thermal management in electronic devices has become an important issue because of the huge increase in heat generation. It is normal to place an electronic device in an electronic cabinet or rack that has several sub-racks inside it, upon which the printed circuit boards (PCBs) are placed. The heat generated by the PCBs must be removed from each of these levels via an appropriate cooling strategy. There are several cooling strategies (liquid cooling [1,2], two-phase cooling [3] and spray cooling [4,5], among others), but the most commonly employed technique is air cooling using an axial fan to produce air movement for reasons of safety and availability. Problems arise as the axial fan is usually placed together with an electromagnetic compatibility (EMC) screen, which mainly plays the role of reducing electromagnetic interferences in the device but it also keeps dust from entering.

The configuration of electronic devices has changed a lot over the years. Several years ago, the axial fan typically worked in a push or pull configuration. However, although some devices continue to use these configurations, nowadays, a pull-push configuration has become more common because of the huge increase in heat generation. The push-pull configuration is depicted in Figure 1.

For each axial fan in the figure, there is an associated difficulty. The rightmost fan in Figure 1, which sucks air out of the system, might be hydraulically affected if the EMC screen is placed too close to the fan (although Figure 1 presents downstream placement, it is possible to place the screen either upstream or downstream from the fan). The hydraulic 
influence means that the characteristic curve of a fan (static pressure versus volumetric flow rate) is reduced. This effect in electronic cooling has been studied by several authors, such as Hill [6], Grimes et al. [7], Lin and Chou [8] and Swim [9], and it has also been studied for automotive cooling purposes by Baniasadi et al. [10]. Antón et al. [11] study the effect of various parameters, and they also give the correlations for predicting the effect of the main parameters (porosity of the screen and distance between fan and screen) for the points of the characteristic curve with the highest static pressure $(Q=0)$ and volumetric flow $\left(\Delta P_{S}=0\right)$. In a similar way, the characterization of the pressure drop coefficients of perforated plates in ducts by means of numerical simulations of complete detailed models was addressed by Tanner et al. [12], who obtained correlations of the pressure drop as a function of the Reynolds number and using as parameters the porosity and the thickness of the plates, or Miguel [13], where the influence of the porosity and the Reynolds numbers on the pressure loss factors was analyzed.

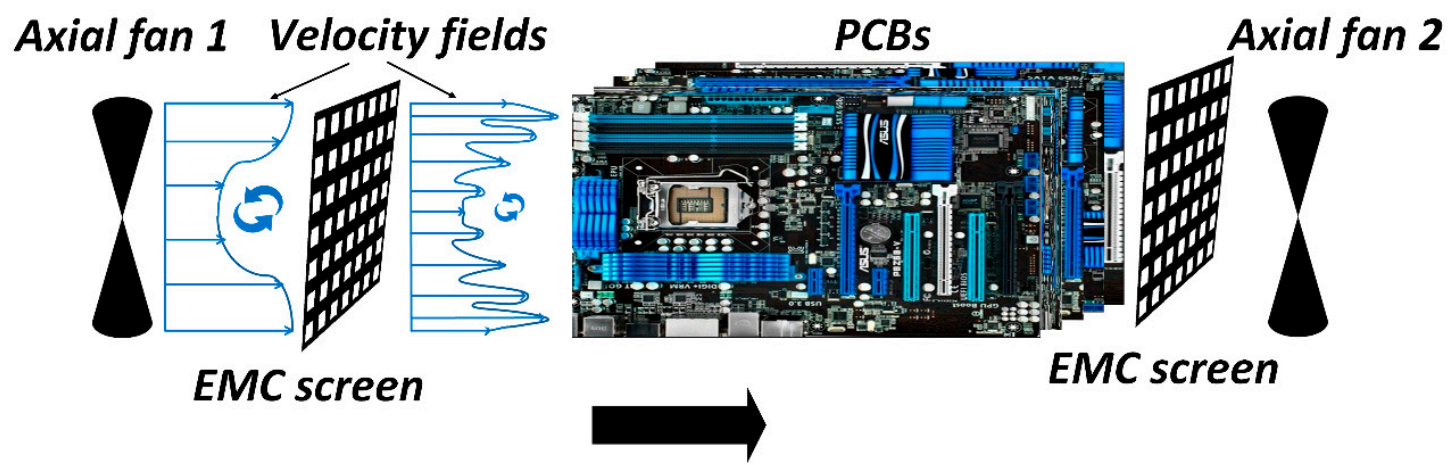

\section{Flow direction}

Figure 1. Scheme of a pull-push cooling configuration.

It is extremely important to know the velocity field downstream from the first EMC screen (see Figure 1), since the cooling capacity for a given electronic component is related to the local velocity magnitude near that component [14]. The pressure drop through the screen is also of interest in order to select a proper axial fan. However, due to the complexity of the approaching flow (an annular profile together with a high rotational component, as depicted in Figure 1), there is a high degree of uncertainty when predicting the downstream velocity field and pressure drop through the screen. It should be noted that the EMC screen modifies the relationship between the axial and tangential components of the flow, which makes predicting the velocity field at the outlet of the screen a challenge [15].

Bengoechea et al. [16] analyzed this issue, investigating the flow change through an EMC screen when the approaching flow is a fan-induced swirling flow. They analyzed two very distinct cases: from the mean flow and screen porosity point of view, among other parameters. They measured the flow pattern after the screen using the particle image velocimetry (PIV) technique, and they then used the experimental values for a computational fluid dynamics (CFD) benchmark. The benchmark conclusion was that for this complex flow, the turbulence model that best predicts the flow was the Reynolds stress transport model (RSTM). The domain of the CFD model was a detailed model, a model in which all the holes or pores of the EMC screen were created and meshed. At the same time, they defined three flow magnitudes that together are able to properly define a velocity field with an annular shape. Once the RSTM was determined to be the correct choice, in Bengoechea et al. [17], a parametric study was presented in order to analyze the influences that different parameters have on the variation of the velocity field that exists between the upstream and downstream of a screen and in the total pressure drop. That parametric study was based on 81 detailed (in which the geometry of the screens with their holes was defined) CFD simulations defined by a Design of Experiments (DoE) approach. Additionally, the study presented, in conjunction with a reduced model for predicting the total pressure 
drop, reduced models based on DoE techniques [18] for predicting the variation in the flow magnitudes that Bengoechea et al. [16] defined in order to set the velocity field. These reduced models could be of great help to thermal designers by allowing them to have a rough idea of how the EMC screen will affect the velocity field and the total pressure drop. Nevertheless, thermal designers will not have an approximation of the velocity field, and so in order to attain that, they will have to run simulations with detailed geometries, such as those used in Bengoechea et al. [16,17]; not only does this require high computational demands, calculating the geometry and the mesh is also a highly time-consuming task. Because product launching times are being progressively reduced, working with compact models of the components in an electronic system is becoming a key modeling approach. The EMC screen is among the components that must be modeled in a compact way, and this is the aim of the present work.

The compact modeling approach is based on directional pressure loss coefficients that define a porous media domain that is very easy to create and mesh. However, the fact that the holes of the screen are not created in a compact model has some drawbacks [19], a major one being that the information about local flow phenomena in very close proximity to a real screen is lost (the small jets produced after the screen, see Figure 1). However, the drawbacks are small in comparison to the benefits, which include, among other things, the reduction in computational demands. Thermal designers may model the screen as a planar resistance, using only one pressure loss coefficient from handbooks like Idelchick's [20]. Kordyban [21] was the first to analyze the need to model a screen as a volumetric resistance, which meant employing more than one coefficient. The results of modeling the screen as a planar and as a volumetric resistance were compared, and it was concluded that if the flow approaching the screen has any tangential component, a planar resistance is not the correct choice. This is because a planar resistance makes the flow more parallel to the screen due to the fact that the unique pressure loss coefficient only affects the axial component of the velocity. The same need to employ more than one coefficient was also shown by Antón et al. [22-25]. In Nevelsteen et al. [26], a volumetric model of a screen was experimentally validated, and a satisfactory fitting was attained. Nevertheless, only one experimental case was studied, and therefore, it was not possible to obtain the pressure loss coefficients as a function of the experimental parameters.

This article uses an iterative process (taking as a reference the results of the 81 detailed numerical cases from Bengoechea et al. [17]) to introduce correlations for the pressure loss coefficients per unit length of a compact model of a screen as a function of different geometric and operational parameters.

The use of compact models to characterize the performance of complex systems in order to make the simulation and design tasks easier and faster is widely extended in different engineering applications: the electric field generated in tunnel field-effect transistors, Najam et al. [27]; the circuit models of vertical-cavity surface-emitting lasers, Li et al. [28]; the dynamic performance of latent heat thermal storage units, Colangelo et al. [29].

The compact model developed and presented here will aid thermal designers, as it will reduce the time needed to create the model, especially when simulating. Specifically, this article presents a powerful tool that makes it possible to obtain a fast and reliable approximation of the velocity field downstream of a screen.

\section{Geometric and Operational Parameters for the Numerical Runs}

The process for obtaining the correlations for the pressure loss coefficients per unit length, as will be explained later, employs the results from the 81 detailed numerical runs presented in [17]. Therefore, the geometric and operational parameters in the numerical runs for this work must be the same as those employed in that work. The parameters and their range are presented in Table 1. " $D$ " is the size of the channel, which corresponds to the diameter of the shroud of the fan being analyzed (see Figure 2). " $D_{h} / D$ " is the ratio between the hub of the fan and the shroud diameter (see Figure 2). " $S$ " is the swirl number as defined by Beér and Chigier [30] and given in Equation (1). In this definition, $L_{c}$ is a 
characteristic length assumed to be half of the simulated fan diameter in this work; " $r$ " is the radial coordinate; and " $V_{a}$ " and " $V_{t}$ " are the local axial and tangential velocities, respectively. " $a$ " is the distance between the outlet of the fan (in this work, the outlet of the fan is the domain inlet) and the inlet of the screen (see Figure 2). " $\varepsilon$ " is the porosity of the screen, defined as the ratio between the open area and the total area of the cross section $(D \times D)$. The next parameter, " $\xi$ ", is the ratio between the total lateral perimeter of the pores and the area of the cross-section. " $t$ " is the thickness of the screen (see Figure 2), and " $V$ " is the mean axial velocity in the channel. The 81 numerical cases are shown in Table 2; the "-", " 0 " and "+" level values used for each parameter are defined in Table 1.

$$
S=\frac{\iint_{A} \rho \cdot V_{a} \cdot V_{t} \cdot r \cdot d A}{L_{c} \cdot \iint_{A} \rho \cdot V_{a}^{2} \cdot d A}
$$

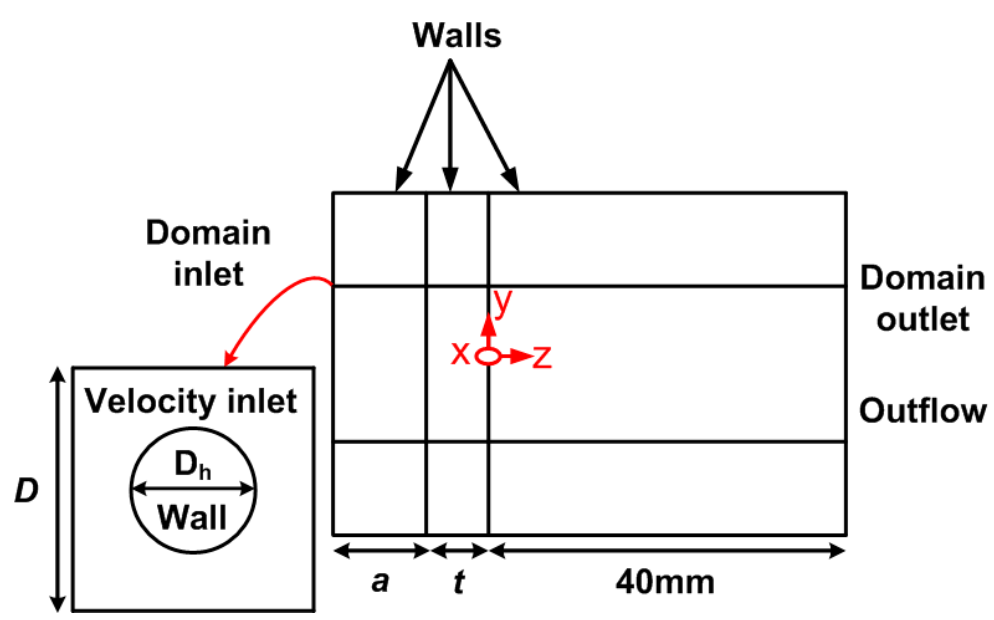

(a)

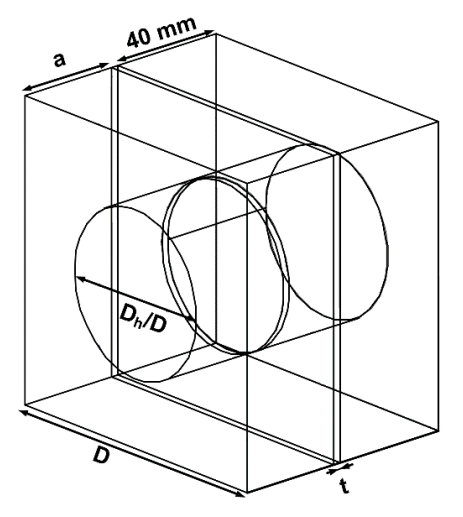

(b)

Figure 2. (a) Generic scheme of the domain and boundary conditions used for the simulations; (b) $3 \mathrm{D}$ representation of the flow domain.

Table 1. Operational and geometric parameters included in the study and their range.

\begin{tabular}{ccccccccc}
\hline Parameters & $\begin{array}{c}\boldsymbol{D} \\
(\mathbf{m m})\end{array}$ & $\begin{array}{c}\boldsymbol{D}_{\boldsymbol{h}} / \boldsymbol{D} \\
\mathbf{( - )}\end{array}$ & $\begin{array}{c}\boldsymbol{S} \\
\mathbf{( - )}\end{array}$ & $\begin{array}{c}\boldsymbol{a} \\
(\mathbf{m m})\end{array}$ & $\begin{array}{c}\boldsymbol{\varepsilon} \\
\mathbf{( \% )}\end{array}$ & $\begin{array}{c}\boldsymbol{\xi} \\
\mathbf{( 1 / \mathbf { m m } )}\end{array}$ & $\begin{array}{c}\boldsymbol{t} \\
(\mathbf{m m})\end{array}$ & $\begin{array}{c}\boldsymbol{V} \\
(\mathbf{m} / \mathbf{s})\end{array}$ \\
\hline Minimum value (-) & 40 & 0.25 & 0.4 & 5 & 30 & 0.25 & 0.5 & 1 \\
Middle value (0) & 70 & 0.4 & 0.7 & 15 & 52.5 & 0.31 & 1.5 & 1.75 \\
Maximum value (+) & 100 & 0.55 & 1 & 25 & 75 & 0.37 & 2.5 & 2.5 \\
\hline
\end{tabular}


Table 2. Numerical runs established by the Design of Experiments (DoE) to be simulated in computational fluid dynamics (CFD).

\begin{tabular}{|c|c|c|c|c|c|c|c|c|c|c|c|c|c|c|c|c|c|}
\hline Exp. & $D$ & $D_{h} / D$ & $S$ & $V$ & $a$ & $t$ & $\varepsilon$ & $\xi$ & Exp. & $D$ & $D_{h} / D$ & $S$ & V & $a$ & $t$ & $\varepsilon$ & $\xi$ \\
\hline 1 & - & + & - & - & + & + & - & - & 42 & - & + & + & - & + & - & + & + \\
\hline 2 & - & - & + & + & - & - & + & + & 43 & + & + & - & + & - & - & - & + \\
\hline 3 & 0 & 0 & + & 0 & 0 & 0 & 0 & 0 & 44 & - & - & - & - & - & + & + & - \\
\hline 4 & 0 & 0 & 0 & 0 & - & 0 & 0 & 0 & 45 & - & + & + & + & + & + & - & - \\
\hline 5 & + & + & + & + & + & - & + & - & 46 & + & + & - & - & - & - & + & + \\
\hline 6 & + & + & - & + & - & + & - & - & 47 & - & - & - & + & - & + & - & - \\
\hline 7 & 0 & 0 & 0 & & 0 & 0 & 0 & 0 & 48 & + & - & + & + & - & + & - & + \\
\hline 8 & + & - & + & + & - & - & - & - & 49 & - & + & + & - & + & + & + & - \\
\hline 9 & 0 & 0 & 0 & 0 & 0 & - & 0 & 0 & 50 & - & + & + & + & - & + & - & + \\
\hline 10 & + & + & + & - & + & + & - & + & 51 & 0 & + & 0 & 0 & 0 & 0 & 0 & 0 \\
\hline 11 & - & 0 & 0 & 0 & 0 & 0 & 0 & 0 & 52 & - & + & - & + & + & - & + & + \\
\hline 12 & 0 & 0 & - & 0 & 0 & 0 & 0 & 0 & 53 & - & - & - & - & + & + & + & + \\
\hline 13 & - & + & + & + & + & - & - & + & 54 & + & - & - & + & + & + & + & - \\
\hline 14 & + & - & + & - & - & + & + & + & 55 & 0 & 0 & 0 & 0 & + & 0 & 0 & 0 \\
\hline 15 & + & - & - & - & + & + & - & - & 56 & + & + & - & - & + & + & + & + \\
\hline 16 & - & - & - & - & + & - & + & - & 57 & 0 & 0 & 0 & 0 & 0 & 0 & 0 & 0 \\
\hline 17 & 0 & 0 & 0 & 0 & 0 & 0 & - & 0 & 58 & - & + & + & - & - & + & + & + \\
\hline 18 & + & - & - & - & + & - & - & + & 59 & - & + & - & + & - & + & + & + \\
\hline 19 & - & + & + & - & - & - & + & - & 60 & + & + & + & + & + & + & + & + \\
\hline 20 & 0 & 0 & 0 & 0 & 0 & 0 & + & 0 & 61 & - & - & + & - & - & + & - & - \\
\hline 21 & - & + & - & - & - & + & - & + & 62 & + & + & + & - & - & + & - & - \\
\hline 22 & + & + & - & - & - & + & + & - & 63 & - & - & + & + & - & + & + & - \\
\hline 23 & + & - & - & + & + & - & + & + & 64 & 0 & 0 & 0 & 0 & 0 & 0 & 0 & + \\
\hline 24 & + & - & - & - & - & - & - & - & 65 & - & - & + & - & - & - & - & + \\
\hline 25 & + & - & - & - & - & + & - & + & 66 & + & - & - & + & - & + & + & + \\
\hline 26 & - & + & - & - & - & - & - & - & 67 & + & + & + & + & - & + & + & - \\
\hline 27 & 0 & 0 & 0 & 0 & 0 & 0 & 0 & - & 68 & 0 & - & 0 & 0 & 0 & 0 & 0 & 0 \\
\hline 28 & + & + & - & + & + & - & - & - & 69 & + & + & - & + & + & + & - & + \\
\hline 29 & + & - & + & + & + & + & - & - & 70 & + & - & + & + & + & - & - & + \\
\hline 30 & + & - & + & - & + & - & + & + & 71 & - & - & + & - & + & + & - & + \\
\hline 31 & - & + & - & + & + & + & + & - & 72 & + & + & + & - & - & - & - & + \\
\hline 32 & + & + & + & - & + & - & - & - & 73 & - & - & - & + & - & - & - & + \\
\hline 33 & 0 & 0 & 0 & + & 0 & 0 & 0 & 0 & 74 & - & + & - & - & + & - & - & + \\
\hline 34 & - & - & + & - & + & - & - & - & 75 & - & - & + & + & + & + & + & + \\
\hline 35 & + & 0 & 0 & 0 & 0 & 0 & 0 & 0 & 76 & + & + & - & - & + & - & + & - \\
\hline 36 & - & - & - & + & + & - & - & - & 77 & - & - & - & - & - & - & + & + \\
\hline 37 & + & - & + & - & + & + & + & - & 78 & - & + & + & + & - & - & - & - \\
\hline 38 & - & + & - & + & - & - & + & - & 79 & + & - & - & + & - & - & + & - \\
\hline 39 & - & - & + & + & + & - & + & - & 80 & + & - & + & - & - & - & + & - \\
\hline 40 & - & - & - & + & + & + & - & + & 81 & 0 & 0 & 0 & 0 & 0 & + & 0 & 0 \\
\hline 41 & + & + & + & + & - & - & + & + & & & & & & & & & \\
\hline
\end{tabular}

\section{Numerical Model}

\subsection{Flow Domain}

In contrast to the 3D perforated plates with squared holes modeled in Bengoechea et al. [17], the simple geometry depicted in Figure 2 is employed as a flow domain for each of the compact models for the 81 cases from Table 2. The novelty of this work is modeling the screen via two different porous media volumes (the inner cylindrical volume and the outer one, as shown in Figure 2). It is to these volumes that the pressure loss coefficients (the objective of this work) are applied. As the geometry of the pores does not have to be modeled, the time needed to create the geometry is substantially reduced. In order to build a conformal mesh between the screen and the downstream and upstream volumes, these volumes are also divided into two volumes in such a way that the same mesh strategy is used throughout the entire volume. The length of the volumes upstream of the screen have the value of parameter " $a$ " (see Figure 2) for each case. The annulus shape that a flow has at the outlet of a fan (see Figure 1), which is needed at the inlet of the domain, is obtained 
following Bengoechea et al. [17] by placing a circular wall whose diameter is " $D_{h}$ " at the inlet cross-section. Consequently, the inlet velocity conditions are imposed on the area around it. In order to make it possible to compare the results of the detailed models from Bengoechea et al. [17] with the compact models from the present work, the channel length after the screen must be the same as that used in the first study. To that end, a value of $40 \mathrm{~mm}$ was fixed.

\subsection{Mathematical Modeling}

\subsubsection{Turbulence Modeling}

In previous experimental measurements carried out by the authors in a wind tunnel [16], it was confirmed that the flow that is being modeled is fully turbulent throughout the domain under consideration. The Reynolds-averaged Navier-Stokes (RANS) approach was adopted for numerically simulating the flow, and thus the mean flow was calculated by solving Equations (2) and (3):

$$
\begin{gathered}
\frac{\partial U_{i}}{\partial x_{i}}=0 \\
\frac{\partial}{\partial x_{j}}\left(\rho U_{i} U_{j}\right)=-\frac{\partial P}{\partial x_{i}}+\frac{\partial}{\partial x_{j}}\left[\mu\left(\frac{\partial U_{i}}{\partial x_{j}}+\frac{\partial U_{j}}{\partial x_{i}}\right)-\rho \overline{{u_{i}^{\prime}{ }_{i}{ }^{\prime}{ }_{j}}^{\prime}}\right]+S_{i}
\end{gathered}
$$

In order to solve the Reynolds stresses $\left(\rho \overline{u_{i}^{\prime} u_{j}^{\prime}}\right)$ and subsequently close the system of Equations (2) and (3), the standard $k-\varepsilon$ model was applied [31]. Although the detailed models in Bengoechea et al. [16,17] used the RSTM as a turbulence model, the standard $k-\varepsilon$ model could be used in this work as the values of the pressure loss coefficients are those that best fit the results obtained in the detailed simulations (those that model the holes). This may be seen as a limitation, but it was done on purpose. The $k-\varepsilon$ model was chosen due to its robustness and lower cost from a computational point of view, and, therefore, it is of more interest for the thermal designers. Since the procedure consists of an iterative process that serves as a calibration of the coefficients for each of the 81 cases, it can be tuned in such a way that takes into consideration not only the porosity physics but also the difference between the two turbulence models.

Within the standard $k-\varepsilon$ model, the Reynolds stresses are calculated by means of the Boussinesq hypothesis:

$$
\rho \overline{u_{i}^{\prime} u^{\prime}{ }_{j}}=-\mu_{t}\left(\frac{\partial U_{i}}{\partial x_{j}}+\frac{\partial U_{j}}{\partial x_{i}}\right)+\frac{2}{3} \rho k \delta_{i j}
$$

So that the Reynolds stress tensor is aligned with the mean strain-rate tensor $\left(S_{i j}\right)$. The standard $k-\varepsilon$ model consists of two transport equations for both the turbulent kinetic energy $(k)$ and its dissipation rate $(\varepsilon)$, which can be expressed in the following compact way:

$$
\begin{gathered}
\frac{\partial}{\partial x_{i}}\left(\rho U_{i} k\right)=\frac{\partial}{\partial x_{j}}\left(\Gamma_{k} \frac{\partial k}{\partial x_{j}}\right)+P_{k}-D_{k} \\
\frac{\partial}{\partial x_{i}}\left(\rho U_{i} \varepsilon\right)=\frac{\partial}{\partial x_{j}}\left(\Gamma_{\varepsilon} \frac{\partial \varepsilon}{\partial x_{j}}\right)+P_{\varepsilon}-D_{\varepsilon}
\end{gathered}
$$

The terms used in both equations are defined in Table 3. The turbulent viscosity is calculated as

$$
\mu_{t}=\rho C_{\mu} \frac{k^{2}}{\varepsilon}
$$

with a value of 0.09 for $C_{\mu}$.

Standard wall functions (SWF), which are based on the work by Launder and Spalding [32], were used for the near-wall treatment of the turbulence model used to predict flow characteristics very close to solid walls. This wall treatment does not require a fine 
meshing close to the wall, which means there is a significant reduction in the amount of elements in the model and, therefore, a reduction in computational time.

Table 3. Terms and coefficients for the standard $k-\varepsilon$ model.

\begin{tabular}{cc}
\hline & Standard $k-\varepsilon$ \\
\hline$\Gamma_{k}$ & $\mu+\frac{\mu_{t}}{\sigma_{k}}$ \\
$\Gamma_{\varepsilon}$ & $\mu+\frac{\mu_{t}}{\sigma_{\varepsilon}}$ \\
$P_{k}$ & $\mu_{t} S^{2}$ \\
$D_{k}$ & $\rho \varepsilon$ \\
$P_{\varepsilon}$ & $C_{1 \varepsilon} \frac{\varepsilon}{k} P_{k}$ \\
$D_{\varepsilon}$ & $C_{2 \varepsilon} \rho \frac{\varepsilon^{2}}{k}$ \\
& $\sigma_{k}=1.0 ; \sigma_{\varepsilon}=1.3$ \\
Coeff. & $C_{1 \varepsilon}=1.44$ \\
& $C_{2 \varepsilon}=1.92$ \\
\hline
\end{tabular}

\subsubsection{Porous Media Modeling}

Both volumes corresponding to the screen (the inner and the outer volumes with " $t$ " thickness, as shown in Figure 2) are assumed as porous media volumes by using directional pressure loss coefficients $\left(\varphi_{x}, \varphi_{y}\right.$ and $\left.\varphi_{z}\right)$ per unit length [33]. The same coefficients $\left(\varphi_{x}=\varphi_{y}=\varphi_{p}\right)$ were used for the " $x$ " and " $y$ " directions, and this value is the same for the inner and outer volumes $\left(\varphi_{p \text { int }}=\varphi_{p}\right.$ ext $\left.=\varphi_{p}\right)$, resulting in a model with greater simplicity. Therefore, the objective of the work is to obtain the pressure loss coefficients " $\varphi_{p}$ ", " $\varphi_{z}$ int" and " $\varphi_{z \text { ext }}$ " per unit length that define a compact model.

The modeling of a screen through the porous media approximation employs a volumetric hydraulic resistance defined by the previous directional pressure loss coefficients per unit length. In the following expression, the generic strain that must be fixed for both the inner and outer porous media volumes in each of the 81 cases from Table 2 is given:

$$
\varphi_{i j}=\left(\begin{array}{ccc}
\varphi_{p} & 0 & 0 \\
0 & \varphi_{p} & 0 \\
0 & 0 & \varphi_{z}
\end{array}\right)
$$

This porous media approach works as a momentum sink in the momentum equation. This sink usually has two different components: the first one is related to the viscous losses (proportional to the velocity), and the second one is due to inertial losses (proportional to the squared velocity). For this study, with the EMC screens, viscous loses are neglected as the inertial losses are far higher. Therefore, the momentum sink might be defined as

$$
S_{i}=-\left(\varphi_{i j} \cdot \frac{1}{2} \cdot \rho \cdot v_{m a g} \cdot v_{j}\right)
$$

where $v_{m a g}$ corresponds to the magnitude of the velocity and $v_{j}$ to the component of the velocity in " $y$ " direction.

Due to the fact that the interior walls of the pores are not modeled in the porous media, a special treatment for the velocities is needed. For this reason, by ensuring the continuity of the vectors through the porous media, a superficial velocity based on the volumetric flow is employed. Therefore, the physics inside the compact model are not the same as those that occur in reality or in the detailed models. In fact, compact models are not able to correctly predict the jets produced by the pores (see the velocity field at the outlet of the screen in Figure 1). This is the reason why the compact models introduced in this work will be reliable at a certain distance from the screen once the flow has been homogenized and the jets have disappeared. 


\subsection{Boundary Conditions}

The scheme of the employed boundary conditions for the compact modeling is shown in Figure 2a, together with the established coordinate system (placed at the center of the cross-section at the outlet of the screen, $z=0$ ). The tangential velocity is defined as having an origin around the $x=0$ and $y=0$ points.

The non-slip condition was fixed for the walls, and an outflow condition was fixed at the outlet cross-section of the domain. For the velocity at the inlet, different constant values of axial and tangential velocities were imposed for each of the 81 cases from Table 2 . The constant values of axial and tangential velocity for each case are such that the mean axial velocity $(V)$ and the swirl number $(S)$ conditions at the inlet coincide with the values shown in Table 2, and they are the same values employed by Bengoechea et al. [17].

The turbulence intensity also must be fixed as conducted by Bengoechea et al. [17]. Thus, at the inlet for all cases, the turbulence was fixed through the hydraulic diameter $\left(D_{h}\right)$ of the section $(D$, as it is a square section), and a constant turbulence intensity of $50 \%$. In that work, it was explained that changes in the values of turbulence intensity at the inlet did not produce important changes in the flow pattern downstream of a screen and, therefore, this inlet turbulence modeling strategy was validated.

\section{Numerical Simulation of the Model}

\subsection{Geometry Meshing}

Since the geometry in this compact model is very simple compared to the detailed model employed in Bengoechea et al. [16,17], the time required to generate the geometry and mesh it for each of the 81 cases from Table 2 did not exceed $5 \mathrm{~min}$.

Before running any simulations, a mesh sensitivity study was carried out in order to set a correct mesh size for each of the model sizes: 40, 70 and $100 \mathrm{~mm}$ (see values for $D$ in Table 1). Therefore, cases 1 and 2 from Table 2 were simulated with random values for the pressure loss coefficients and different interval sizes (IS) for the mesh $(0.2,0.3$, $0.4,0.5$ and $0.6 \mathrm{~mm}$ ). It must be highlighted that the thickness parameter $(t)$ for cases 1 and 2 are at different levels, and therefore, it was also necessary to check whether screen thickness might have any influence on the mesh size requirements. The difference between the model using an IS of 0.2 and 0.6 was less than $6 \%$ in the peak for axial or tangential velocities at the centerline $(x=0)$ of a cross-section located $20 \mathrm{~mm}$ downstream from the screen. Additionally, it was necessary to verify that a low thickness did not demand a higher density for the mesh. Therefore, as the main objective of the compact model is to reduce the time required, an IS of $0.6 \mathrm{~mm}$ was chosen as the mesh resolution for all the models with a $40 \mathrm{~mm}$ value for parameter $D$.

Once this IS was established for the small size in all cases, the same study was carried out for case 6 from Table 2, where the model size was fixed to its higher value (100 mm). The mesh sizes simulated for this case were $0.4,0.8,1.0$ and $1.5 \mathrm{~mm}$. Similar to cases 1 and 2 , because the variation was not greater than $6.7 \%$ for the peak values (in $x=0$ for the $20 \mathrm{~mm}$ downstream cross-section), an IS of $1.5 \mathrm{~mm}$ was selected as the correct choice.

Finally, for the middle value of the diameter $(70 \mathrm{~mm})$, the growth rate was respected. For the low value of $D(40 \mathrm{~mm})$ an IS of $0.6 \mathrm{~mm}$ was used, and for the high value $(100 \mathrm{~mm})$, an IS of $1.5 \mathrm{~mm}$ was used, and thus the growth rate was $2.5(100 \mathrm{~mm} / 40 \mathrm{~mm}=1.5 / 0.6 \mathrm{~mm})$. Similarly, for the middle value of $D(70 \mathrm{~mm})$, an IS of $1.05 \mathrm{~mm}$ was employed $(70 / 40 \mathrm{~mm}=1.05 / 0.6 \mathrm{~mm})$. A sample of the mesh used is presented in Figure 3. 


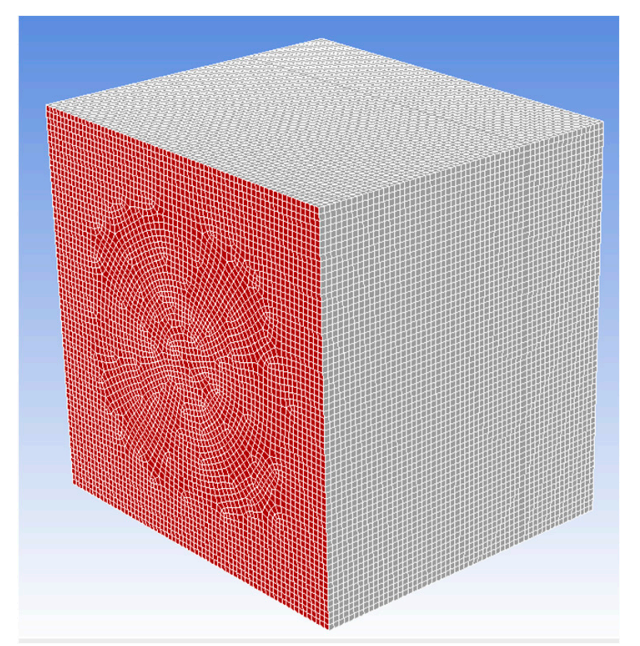

Figure 3. Representation of the mesh for one of the cases simulated of the compact model.

\subsection{Numerical Procedure}

The finite volume method implemented in Ansys Fluent ${ }^{\circledR} 13.0$ [33] was used as the numerical discretization method. A segregated scheme using a second-order centered scheme for the diffusion terms was used when solving the equations of the mathematical models. A second-order upwind scheme was employed to discretize the convection terns of the RANS equations and the transport equations for the turbulence quantities $\mathrm{k}$ and epsilon. The SIMPLE pressure-velocity-coupling algorithm was employed to solve the continuity equation by using a momentum interpolation method to calculate velocities at cell faces.

\subsection{Convergence Criterion and Computational Time}

In order to set an adequate level of convergence, the guidelines proposed by the European Research Community on Flow, Turbulence and Combustion [34] were followed. This way, when stating that a case was converged, the scaled residuals of all the variables were always less than $1.1 \times 10^{-5}$. Different flow magnitudes were monitored in a crosssection located $20 \mathrm{~mm}$ downstream from the screen in each case, and it was verified that there was no change in the 4th significant digit when stopping the simulations.

To perform the simulations, an HP Proliant DL 585 G7 server (DL 585 G7, HP, Leon, Spain, 2013) that had 32 processors at $2.8 \mathrm{GHz}, 64 \mathrm{~GB}$ of shared RAM memory and ran the Linux operating system was used. The communication library used was Platform MPI, and the required CPU time for the simulation was below one minute. It must be highlighted that for the simulations by Bengoechea et al. [17], the computational time with the same server oscillated between 66 and $360 \mathrm{~h}$. Moreover, even using a not very powerful computer, no more than $10 \mathrm{~min}$ (less than $0.25 \%$ of the detailed model computation time) is needed in order to reach a correct convergence.

\section{Iterative Process to Obtain the Pressure Loss Coefficients per Unit Length}

The objective of the iterative process is to obtain the values for the pressure loss coefficients for each of the 81 cases introduced in Table 2. As such, the same iterative process is applied to each of the 81 cases.

The process for each of the cases starts with 5 initial simulations with randomized and different values for " $\varphi_{p}$ ", " $\varphi_{z}$ int" and " $\varphi_{z}$ ext". This way, the response of the model (which could be described as a response surface of the coefficients) to coefficient values changes is captured. From each of the 5 simulations, values are obtained for the area weighted average of the tangential velocity " $\bar{v}_{t}$ ", the swirl number " $S$ " and the minimum and the maximum axial velocities " $V_{\min }$ " and " $V_{\max }$ " from the outlet cross-section $(z=40 \mathrm{~mm}$ in Figure 2). These magnitudes are the flow magnitudes that Bengoechea et al. [16] defined in order to 
correctly define a flow pattern with an annular shape. Therefore, it might be said that the values of the flow magnitudes in each of the 5 simulations correctly define the different flow patterns (as a result of the different pressure loss coefficients) at the outlet cross-section of the model. The next step is to find a function that represents the response surface model. That function can be described by obtaining the values $A, B, C$ and $D$ in Equation (10). This equation represents the relationship between the pressure loss coefficients $\left(\varphi_{p} i, \varphi_{z}\right.$ int $i$ and $\left.\varphi_{z \text { ext }}\right)$ used for the five initial simulations and the result obtained for $\phi_{i}$ in the five cases, where $\phi_{i}$ is one of the flow magnitudes $\left(\overline{v_{t}}, S, V_{\min }\right.$ and $\left.V_{\max }\right)$ :

$$
\left(\begin{array}{l}
\phi_{1} \\
\phi_{2} \\
\phi_{3} \\
\phi_{4} \\
\phi_{5}
\end{array}\right)-\left(\begin{array}{lll}
A & B & C
\end{array}\right)\left(\begin{array}{ccccc}
\varphi_{p 1} & \varphi_{p 2} & \varphi_{p 3} & \varphi_{p 4} & \varphi_{p 5} \\
\varphi_{z \text { int } 1} & \varphi_{z \text { int } 2} & \varphi_{z \text { int } 3} & \varphi_{z \text { int } 4} & \varphi_{z \text { int } 5} \\
\varphi_{z \text { ext } 1} & \varphi_{z \text { ext } 2} & \varphi_{z \text { ext } 3} & \varphi_{z \text { ext } 4} & \varphi_{z \text { ext } 5}
\end{array}\right)-D=0
$$

Thus, for each of the flow magnitudes, a group of values for $A, B, C$ and $D$ is obtained. With these values, a new step is carried out to search for the values for $\varphi_{p}, \varphi_{z}$ int and $\varphi_{z \text { ext }}$ that minimize Equation (11) according to the response surface $(A, B, C$ and $D)$ that has been obtained for each of the flow magnitudes. In other words, a combination of pressure loss coefficients that create a flow pattern and pressure drop like that obtained in the detailed model is sought. Equation (11) consists of a summary of the differences (Equations (12)-(15)) obtained when comparing the flow magnitudes obtained with the detailed model from Bengoechea et al. [16] and those obtained with the compact model whose coefficients are being determined. The solution that is obtained $\left(\varphi_{p}, \varphi_{z}\right.$ int $i$ and $\left.\varphi_{z_{\text {ext }}}\right)$ is the one that minimizes Equation (11) according to the response surface $(A, B, C$ and $D$ ) obtained in the previous step.

$$
\begin{gathered}
F=\frac{A b s\left(\Delta \overline{v_{t}}\right)+A b s(\Delta S)+A b s\left(\Delta v_{\text {max }}\right)+A b s\left(\Delta v_{\text {min }}\right)}{4} \\
\Delta \overline{v_{t}}=\left(1-\frac{\overline{v_{\text {tcompact }}}}{\overline{v_{\text {tdetailed }}}}\right) \times 100 \\
\Delta S=\left(1-\frac{S_{\text {compact }}}{S_{\text {detailed }}}\right) \times 100 \\
\Delta v_{\text {max }}=\left(1-\frac{v_{\text {max compact }}}{v_{\text {max detailed }}}\right) \times 100 \\
\Delta v_{\text {min }}=\left(\frac{\text { Abs }\left(v_{\text {min compact }}-v_{\text {min detailed }}\right)}{V}\right) \times 100
\end{gathered}
$$

With the new values obtained for $\varphi_{p}, \varphi_{z \text { int } i}$ and $\varphi_{z \text { ext } i}$, a new simulation is run using these values for the pressure loss coefficients. Thus, the values for the flow magnitudes in this new simulation are obtained, and a new row is added to the system in (10), and then, the response surfaces are recalculated $(A, B, C$ and $D)$ in such a way that a higher accuracy is achieved based on the new additional case. Subsequently, new values for the coefficients are determined, and then the response surfaces are recalculated, thus beginning the iterative process. The break point of the iterations is when the variation in the values for the pressure loss coefficients between two iterations is negligible.

\section{Correlations for the Pressure Drop Coefficients per Unit Length and Reliability of the Compact Model}

6.1. Different Trends for the Behavior of the Value for $\varphi_{z}$ ext

The iterative process was completed for the 81 cases in Table 2. Once the values for the coefficients per unit length were obtained for all cases, it was possible to distinguish three different trends in the values of the pressure loss coefficients among the 81 cases. The first trend includes only two cases, for which a correct adjustment between the compact 
and the detailed models was obtained using a value for $\varphi_{z \text { ext }}$ that was higher than 0 and lower than $\varphi_{z \text { int }}$. An example of this is presented in Figure 4, where the results for case 40 $\left(\varphi_{z \text { ext }}=3533\right.$ and $\left.\varphi_{z \text { int }}=100,000\right)$ from Table 2 are shown. As the figure illustrates, the approach of the velocity field that was obtained presents a satisfactory adjustment with that obtained by the detailed modeling from Bengoechea et al. [17].

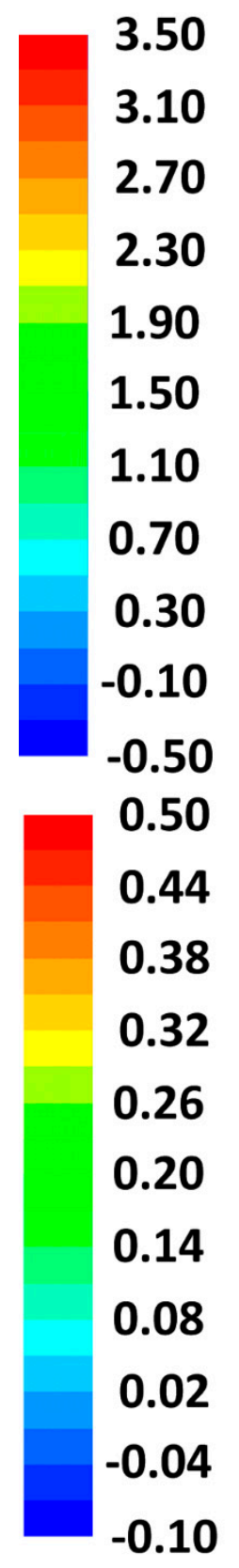

Axial velocities

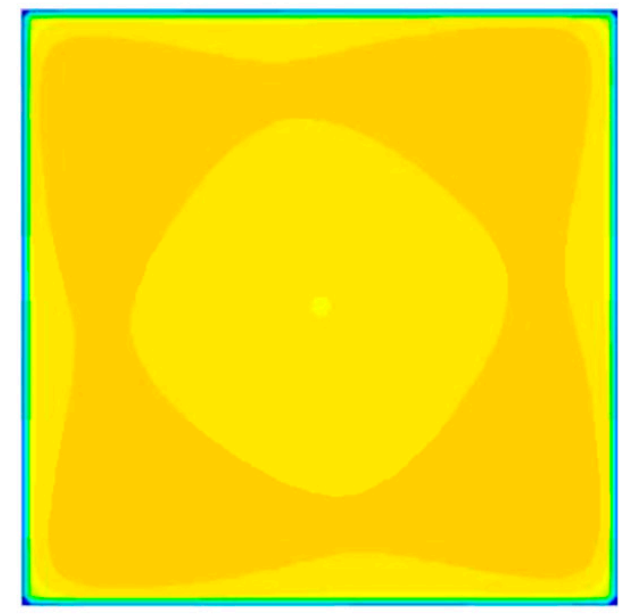

Compact model

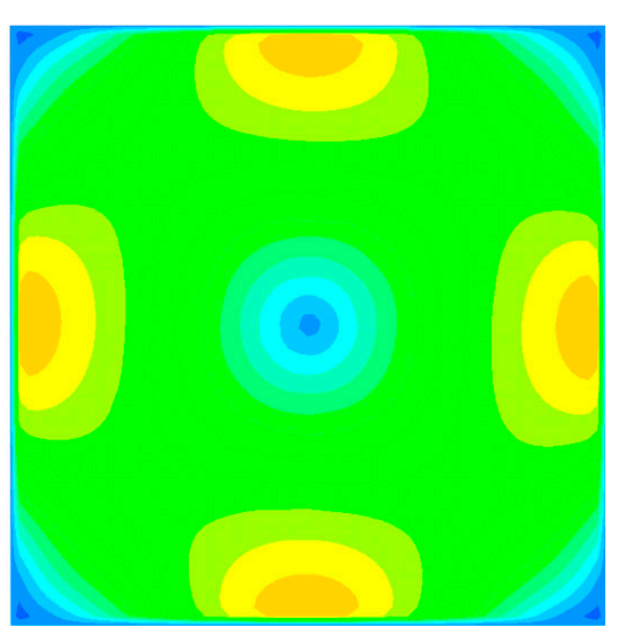

Detailed model

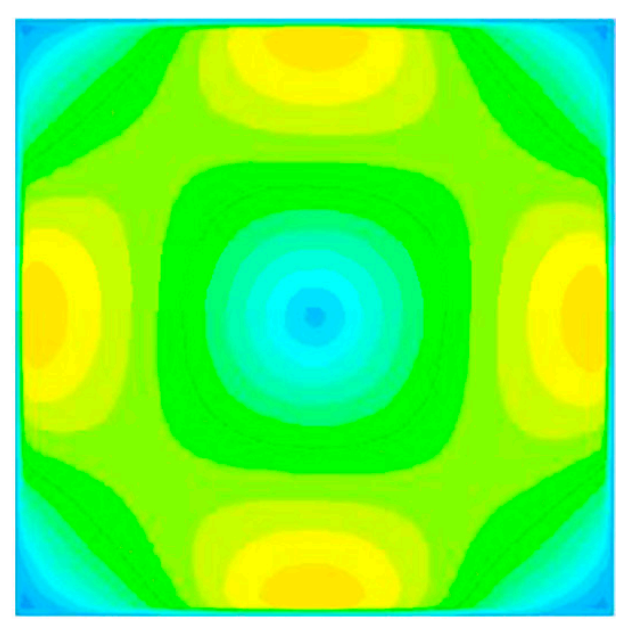

\section{Tangential velocities}

Figure 4. Axial and tangential velocity patterns (m/s) for the outlet cross-section obtained for case 40 in Table 2 via compact modeling and detailed modeling.

In the second trend, negative values for $\varphi_{z \text { ext }}$ are needed to achieve a correct adjustment. Using a negative value for this coefficient does not make any physical sense, as it means a momentum is generated instead of a sink, which is what it should be. However, there is some similarity with what actually happens in the detailed models, as they show that the flow by the hub zone is deviated towards the annulus side when crossing a screen in a certain way (as can be seen in Figure 5). In other words, the annulus side receives 
momentum from the hub side. The only way to generate this effect for compact modeling through porous media is by using a negative value for $\varphi_{z \text { ext }}$.

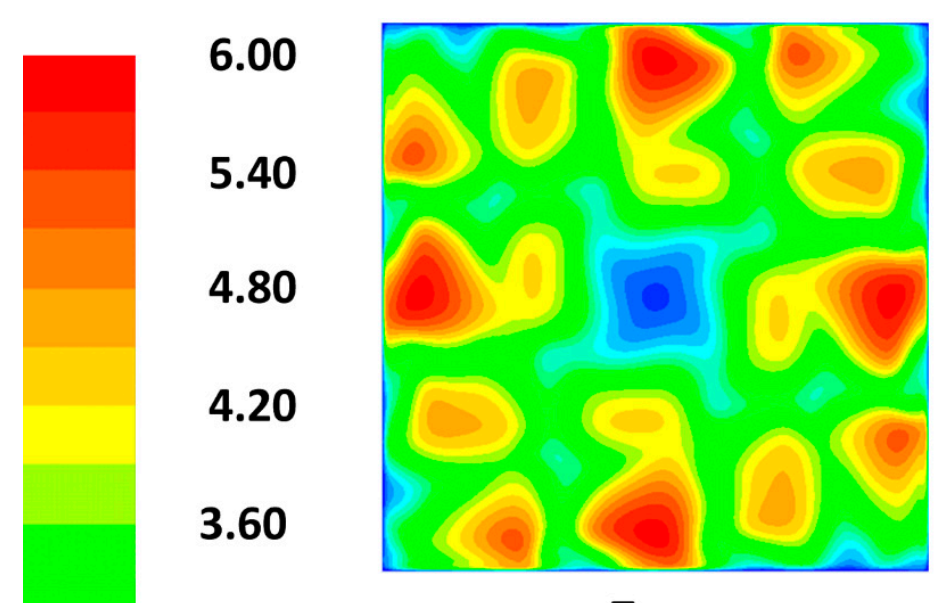

3.00

2.40

1.80

1.20

0.60

0.00 $\mathrm{z}=5 \mathrm{~mm}$

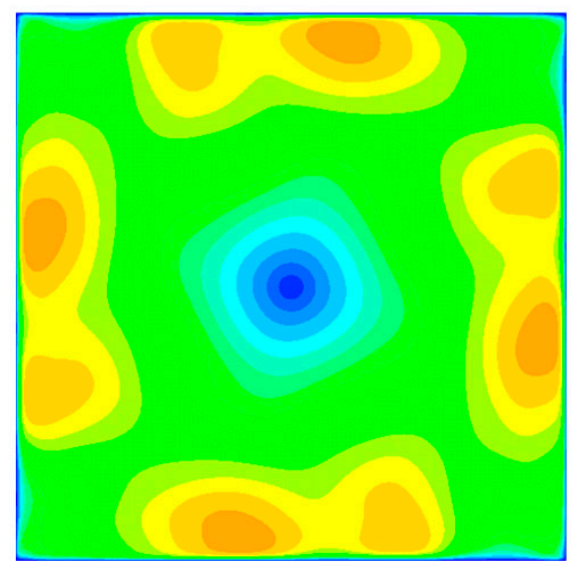

$\mathrm{z}=15 \mathrm{~mm}$

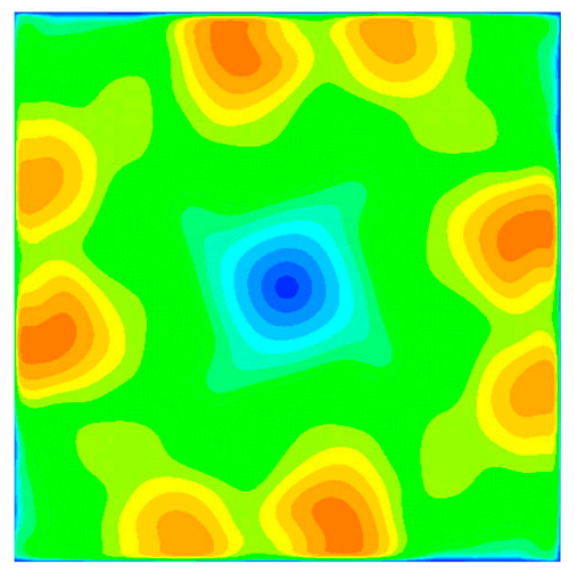

$\mathrm{z}=10 \mathrm{~mm}$

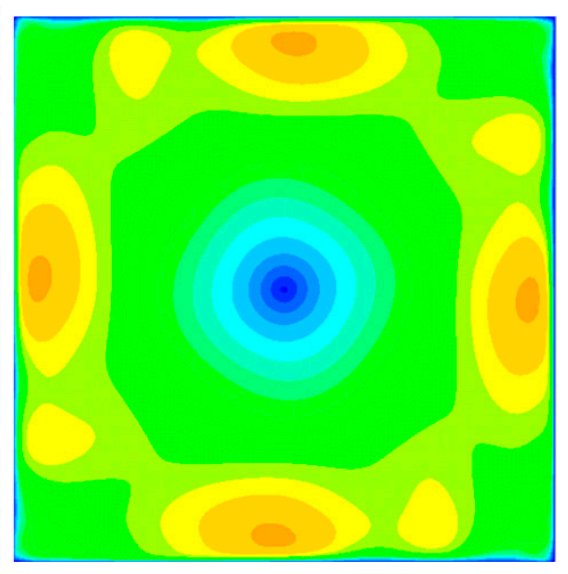

$\mathrm{z}=20 \mathrm{~mm}$

Figure 5. Velocity magnitudes contour plots $(\mathrm{m} / \mathrm{s})$ at different distances from the outlet of the screen for case 2 in Table 2.

The rest of the cases belong to the third trend, which includes all those cases where a very good adjustment is not achieved for the minimum and maximum axial velocity. As the $\varphi_{z \text { ext }}$ coefficient is reduced further, a correct adjustment is achieved for the maximum velocity but not for the minimum one, for which the value of $\varphi_{z}$ ext should be even smaller. An example of this trend is shown in Figure 6, which shows the second case in Table 2. The adjustment presented between both models in the figure indicates that the approach is good even for the difference in the minimum velocity value. The maximum axial velocity zone and the tangential velocity field are well approximated.

It must be highlighted that the values for the coefficients were obtained by comparing the flow magnitudes at the outlet cross-sections of the domain for all cases. However, the approaches of the flow pattern obtained by this compact modeling were verified as being reliable once the jets produced by the holes disappeared. 

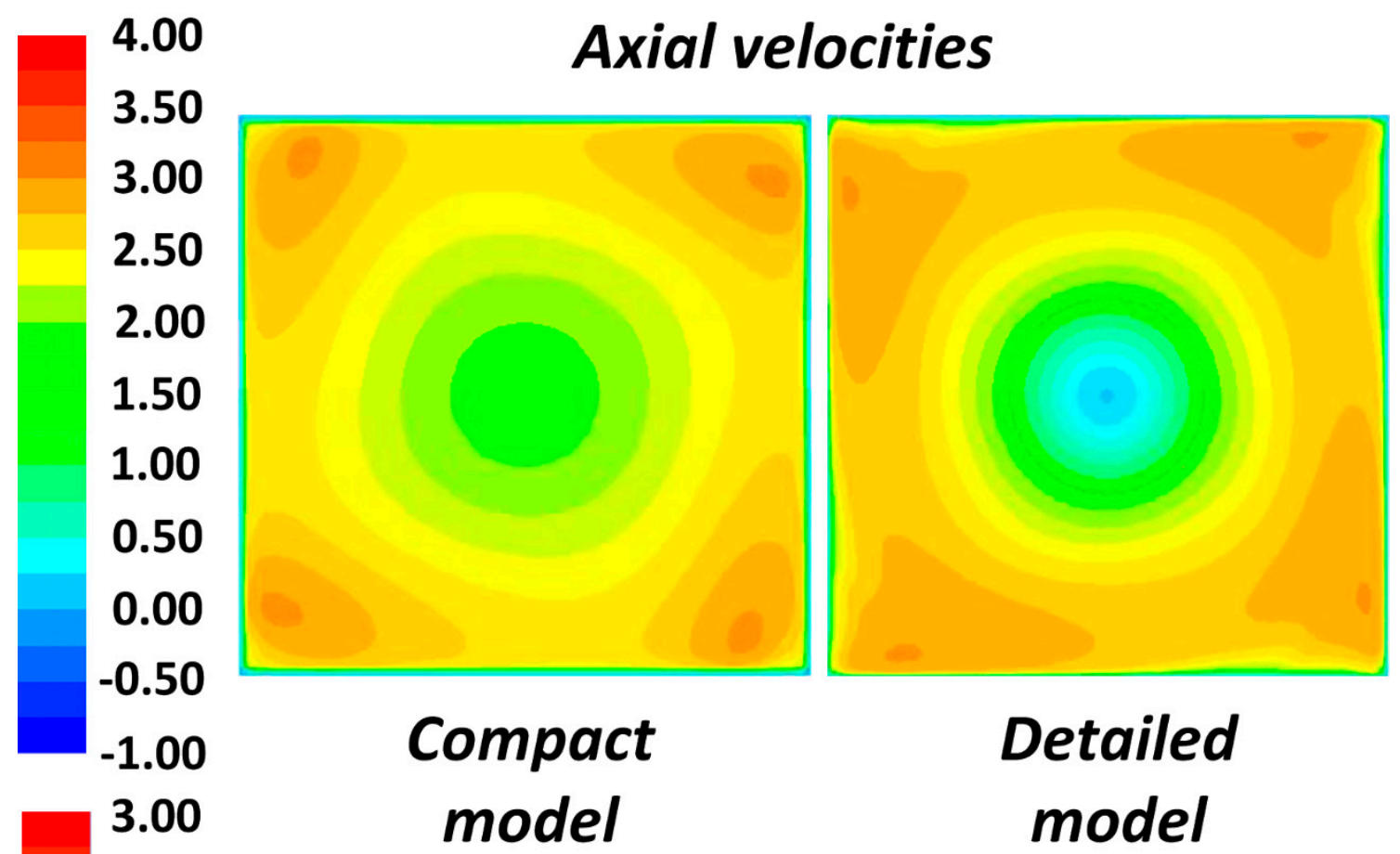

2.65

2.30

1.95

1.60

1.25

0.90

0.55

0.20

$-0.15$

$-0.50$

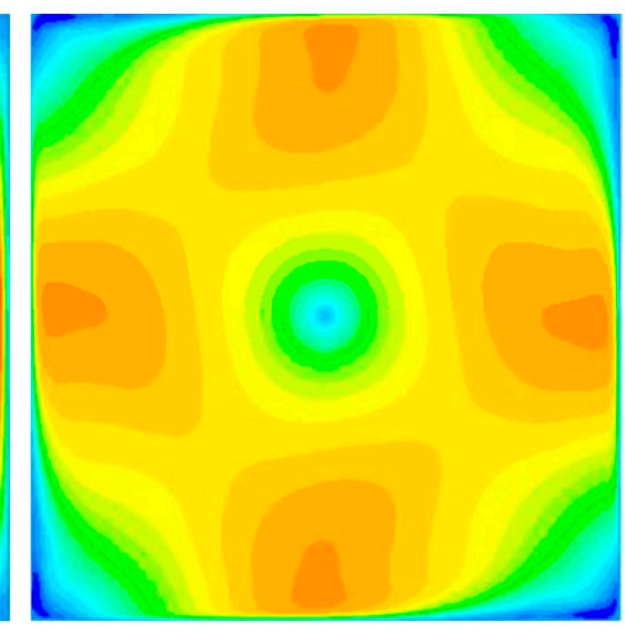

\section{Tangential velocities}

Figure 6. Axial and tangential velocity patterns $(\mathrm{m} / \mathrm{s})$ for the outlet cross-section obtained for case 2 in Table 2 via compact modeling and detailed modeling.

6.2. Correlations for the Coefficients as a Function of the Geometric and Operational Parameters

The previous section explained the different trends among the cases. Because the trends establish different behaviors for the parameters, obtaining correlations for the pressure loss coefficients as a function of the geometric and operational parameters is not easy. In order to obtain the correlations, certain restrictions were imposed on the coefficient values, in spite of knowing that the quality of the adjustment was going to be slightly reduced. Thermal designers will be interested in obtaining the values for the pressure loss coefficients for their geometric parameters on their own, which is why the correlations are more imperative than the values obtained by the iterative process.

The first restriction is to impose the value of zero on $\varphi_{z}$ ext for the cases that had a value of $\varphi_{z \text { ext }}$ greater than zero after the iterative process. As explained above, only two of the 81 cases turn out to have a positive value for $\varphi_{z \text { ext }}$. These two cases with a positive 
coefficient reduce the adjustment of the coefficient values predicted by the correlation to those obtained with the iterative process.

The second restriction is related to the value of $\varphi_{z i n t}$. It was verified that for the cases where $\varphi_{z \text { ext }}$ is smaller than zero (nearly all cases), the influence of the value for $\varphi_{z \text { int }}$ is strongly reduced, which makes it difficult for the iterative process to achieve good results for both coefficients. However, the shape of the flow pattern depends on the relation between $\varphi_{z \text { ext }}$ and $\varphi_{z \text { int }}$. For this reason, if one of the coefficients is fixed, it is possible to obtain a correct adjustment for the flow pattern through an adequate value for the other coefficient. Therefore, the value of $\varphi_{z \text { int }}$ is fixed to 100,000 (which is the value that this coefficient had for the two cases where $\varphi_{z \text { ext }}$ was originally greater than zero). This way, once the value of $\varphi_{z}$ int is fixed, it is easier for the iterative process to achieve a correct value for $\varphi_{z \text { ext }}$, and at the same time, the error for those two cases is minimized, as they have their original values for $\varphi_{z \text { int }}$. Eventually, the complexity of the model is also reduced from a compact model with three unknown pressure loss coefficients to a model with only two unknown coefficients.

With the above restrictions imposed on the values, the iterative process was applied again, this time only looking for $\varphi_{z}$ ext and $\varphi_{p}$, such that expression 10 was reduced to the following:

$$
\left(\begin{array}{l}
\phi_{1} \\
\phi_{2} \\
\phi_{3} \\
\phi_{4} \\
\phi_{5}
\end{array}\right)-\left(\begin{array}{ll}
A & B
\end{array}\right)\left(\begin{array}{ccccc}
\varphi_{p 1} & \varphi_{p 2} & \varphi_{p 3} & \varphi_{p 4} & \varphi_{p 5} \\
\varphi_{z \text { ext } 1} & \varphi_{z \text { ext } 2} & \varphi_{z \text { ext } 3} & \varphi_{z \text { ext } 4} & \varphi_{z \text { ext } 5}
\end{array}\right)-D=0
$$

With the new pressure loss coefficients, two correlations (one for $\varphi_{p}$ and the other for $\left.\varphi_{z \text { ext }}\right)$ were obtained using DoE techniques [18]. Before they are presented, it is necessary to explain how they were used. The values of the parameters for the models had to be within the range shown in Table 1, and at the same time, their values had to be entered in a coded way. This means that instead of using the real value, it had to be transformed to the $(-1,1)$ range according to expression 17 [18], where the real center value and the real low value are those that appear in Table 1 for the middle value (0) and for the minimum value (-):

$$
\text { Coded Value }=\frac{\text { Real Value }- \text { Real centre value }}{\text { Real centre value }- \text { Real low value }}
$$

The generic expression for both correlations can be written in a general form as [18]:

$$
Y=b_{0}+\sum_{i=1}^{k} b_{i} x_{i}+\sum_{i=1}^{k} b_{i i} x_{i}^{2}+\sum \sum_{i<j} b_{i j} x_{i j}
$$

where $Y$ is the value obtained for the pressure loss coefficient through each correlation; $x_{i}$ is the coded values for the geometric and operational parameters obtained through expression 17; and $b_{0}, b_{i}, b_{i i}$ and $b_{i j}$ for each correlation are the regression coefficients obtained through the DoE technique for the independent term, for each of the main effects, for the quadratic effects and for the significant interactions, respectively. $\mathrm{k}$ for each model is the number of main effects, quadratic terms or main interactions that must be included in order to attain a good fit for the regression models.

The correlations for $\varphi_{p}$ and $\varphi_{z}$ ext are presented in Tables 4 and 5, respectively. The values of the regression adjusted coefficients $\left(R^{2}\right)$ are $79 \%$ and $95 \%$, respectively. 
Table 4. Terms of the correlation for $\varphi_{p}$.

\begin{tabular}{cccccccc}
\hline Factor & $\beta_{0}$ & $D$ & $D_{h} / D$ & $S$ & $V$ & $a$ & $t$ \\
\hline Value & 445.48 & -159.30 & -52.03 & 22.94 & -122.42 & -22.02 & 257.08 \\
\hline Factor & $\varepsilon$ & $\xi$ & $D-V$ & $D-t$ & $D-\varepsilon$ & $D-\xi$ & $S-D_{h} / D$ \\
\hline Value & -307.91 & 230.03 & 84.87 & 155.50 & 61.81 & 53.03 & -56.22 \\
\hline Factor & $\boldsymbol{V}-\boldsymbol{t}$ & $\boldsymbol{a}-\boldsymbol{t}$ & $\boldsymbol{\varepsilon}-\boldsymbol{t}$ & $\boldsymbol{\xi}-\boldsymbol{t}$ & $\boldsymbol{\varepsilon}-\boldsymbol{\xi}$ & & \\
\hline Value & 107.62 & -60.56 & -175.56 & 127.28 & -127.16 & & \\
\hline
\end{tabular}

Table 5. Terms of the correlation for $\varphi_{z \text {, ext }}$.

\begin{tabular}{cccccccc}
\hline Factor & $\beta_{\boldsymbol{0}}$ & $\boldsymbol{D}$ & $\boldsymbol{D}_{\boldsymbol{h}} / \boldsymbol{D}$ & $S$ & $\boldsymbol{V}$ & $\boldsymbol{a}$ & $\boldsymbol{t}$ \\
\hline Value & -771.53 & 519.09 & 142.53 & -26.18 & 26.55 & 284.48 & 557.85 \\
\hline Factor & $\varepsilon$ & $\xi$ & $\boldsymbol{D}-\boldsymbol{D}_{\boldsymbol{h}} / \boldsymbol{D}$ & $\boldsymbol{D}-\boldsymbol{t}$ & $\boldsymbol{D}-\boldsymbol{\xi}$ & $\boldsymbol{a}-\boldsymbol{D}_{\boldsymbol{h}} / \boldsymbol{D}$ & $\boldsymbol{t}-\boldsymbol{D}_{\boldsymbol{h}} / \boldsymbol{D}$ \\
\hline Value & -74.12 & 175.85 & 75.16 & -425.94 & 86.75 & -116.31 & -125.81 \\
\hline Factor & $S-\varepsilon$ & $V-\varepsilon$ & $V-\xi$ & $\boldsymbol{a}-\boldsymbol{t}$ & $\boldsymbol{a}-\boldsymbol{\varepsilon}$ & $\boldsymbol{t}-\boldsymbol{\xi}$ & $\boldsymbol{t}-\boldsymbol{t}$ \\
\hline Value & 88.50 & 55.91 & -53.75 & -108.91 & -57.81 & -108.34 & -193.59 \\
\hline
\end{tabular}

\subsection{Reliability of Compact Modeling}

Having presented the correlations, the next step is to observe the results that are obtained through the use of the coefficients that are predicted by the correlations. With this aim, the flow magnitudes $\left(\overline{v_{t}}, S, V_{\min }\right.$ and $\left.V_{\max }\right)$ at the outlet cross-section of the domain are compared. On the one hand, the flow magnitudes obtained by the simulations with the pressure loss coefficients from the second iterative process are compared with those obtained by the simulations using the coefficients predicted by the correlations. On the other hand, the magnitudes obtained by the coefficient predictions of the correlations are compared with the magnitudes obtained by the detailed models in Bengoechea et al. [17] that are used as a reference. It must also be noted that the detailed model was experimentally validated in Bengoechea et al. [16].

The results for the first comparison are shown in Figure 7. From the figure, it can be concluded that using the values for $\varphi_{p}$ and $\varphi_{z \text { ext }}$ obtained by the correlations from the compact model do not produce a big difference in the flow magnitudes with respect to using the coefficients obtained just after the iterative process. There are few samples that escape the $\pm 20 \%$ of difference.

Once it was shown that the employed correlations had a reasonable influence on the flow magnitude predictions, these were compared with the flow magnitudes obtained by the detailed models in Bengoechea et al. [17]. This comparison is shown in Figure 8. From this figure, it can be seen that the flow magnitudes obtained by the compact model are satisfactory for $\overline{v_{t}}, S$ and $V_{\max }$. For these magnitudes, nearly all samples are inside the $\pm 20 \%$ difference. However, for $V_{\min }$, it seems that a considerable error is produced. Nevertheless, this error is not very significant if the velocity contours are analyzed. Figure 6 shows that in spite of there being a great difference between the minimum axial velocity values obtained by the compact model and those obtained by the detailed model, the approach to the velocity fields is excellent. Therefore, the results from the minimum axial velocities values are not significant. Moreover, in order to estimate whether the minimum velocity should be smaller, the reduced model presented in Bengoechea et al. [17] can be used. 


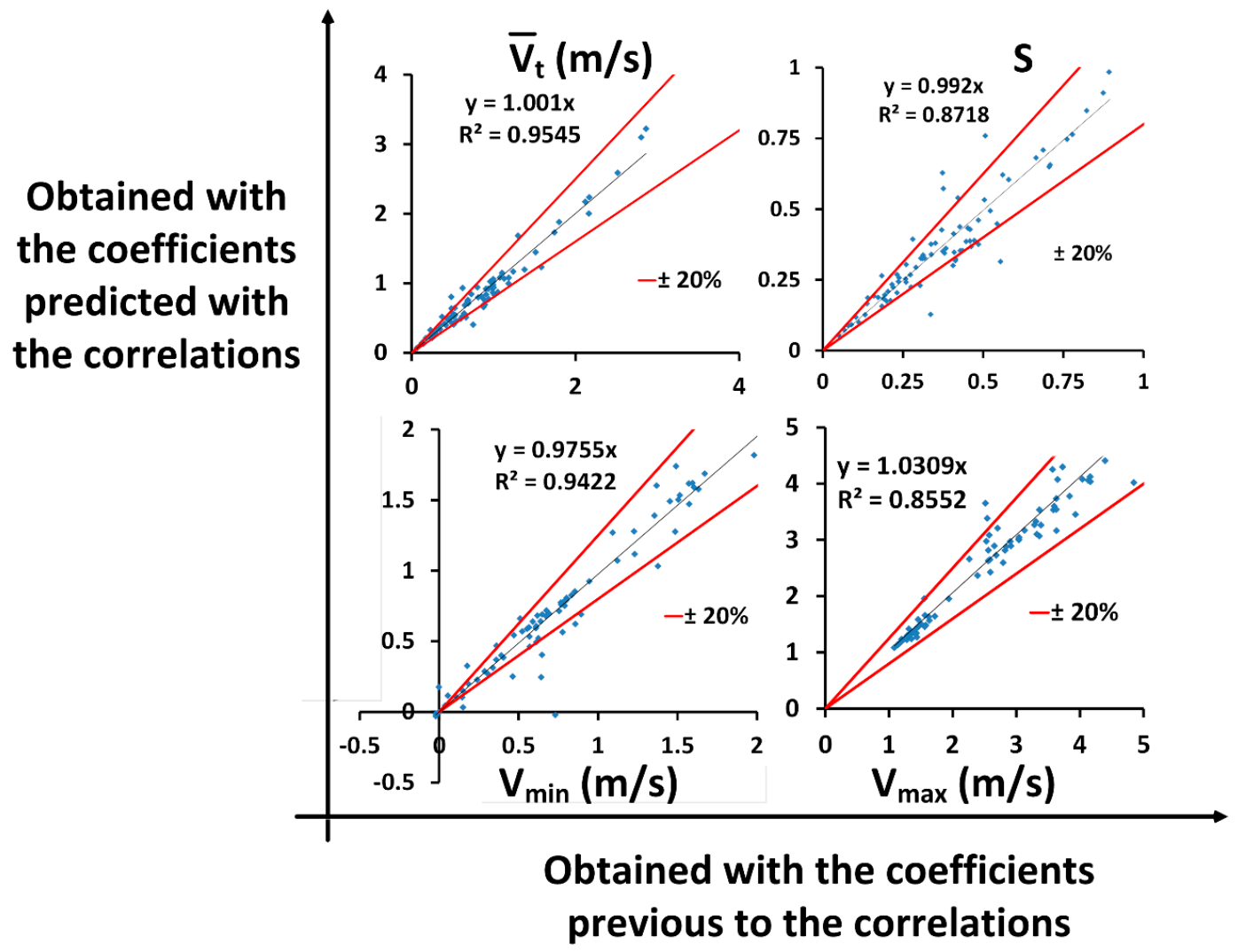

Figure 7. Flow magnitudes for the outlet cross section of the domain obtained with the coefficients predicted by the correlations vs. the flow magnitudes obtained with the coefficients previous to the correlations.

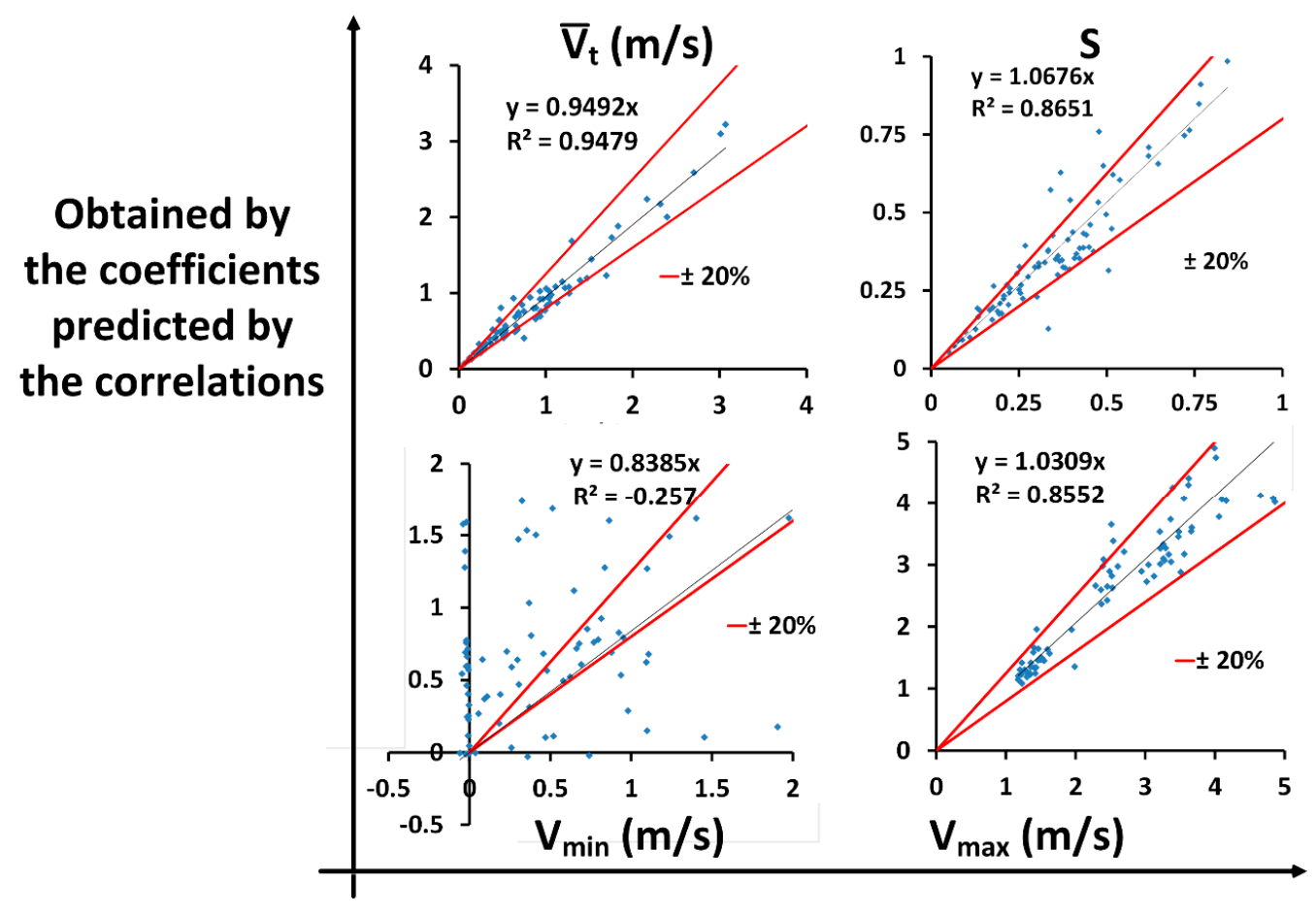

Obtained via the detailed models

Figure 8. Flow magnitudes for the outlet cross-section of the domain obtained with the coefficients predicted by the correlations vs. the flow magnitudes obtained via the detailed models. 
There is also interest in comparing how using the compact model improves the results that thermal designers attain without this model. Nowadays, thermal design is a challenge that is tackled by using pressure loss coefficients obtained from different handbooks, such as that by Idelchick [20]. The problem is that thermal designers use only one pressure loss coefficient. In order to show the improvements provided by the compact model, this pressure loss coefficient was calculated from Idelchick [20] for each of the 81 cases in Table 2. The geometries for each of the cases in Figure 2 were simulated by imposing the corresponding value of the calculated pressure loss coefficient on $\varphi_{z \text { ext }}$ and $\varphi_{z \text { int }}$, and $\varphi_{p}=0$, which is the process used most frequently by thermal designers. In Figure 9 , the flow magnitudes obtained via simulation for the outlet cross-section are compared with those obtained from the detailed models in Bengoechea et al. [17]. This figure shows that the predictions for each of the flow magnitudes $\left(\overline{v_{t}}, S, V_{\min }\right.$ and $\left.V_{\max }\right)$ made by using handbooks are much worse than the predictions obtained by the compact model presented in this work. In fact, the values for $\mathrm{R}^{2}$ are clearly lower (unless for the maximum velocity). Furthermore, it is important to highlight that the correlation line is far from the ideal case of $y=x$, which means that in spite of having a good value for $\mathrm{R}^{2}$ (as is the case for $V_{\max }$ ), the error produced with respect to the detailed models is high for nearly all samples. As the figure indicates, for $V_{\max }$, most of the samples are in the $\pm 20 \%$ range of difference, in spite of having an $\mathrm{R}^{2}$ of 0.93 .

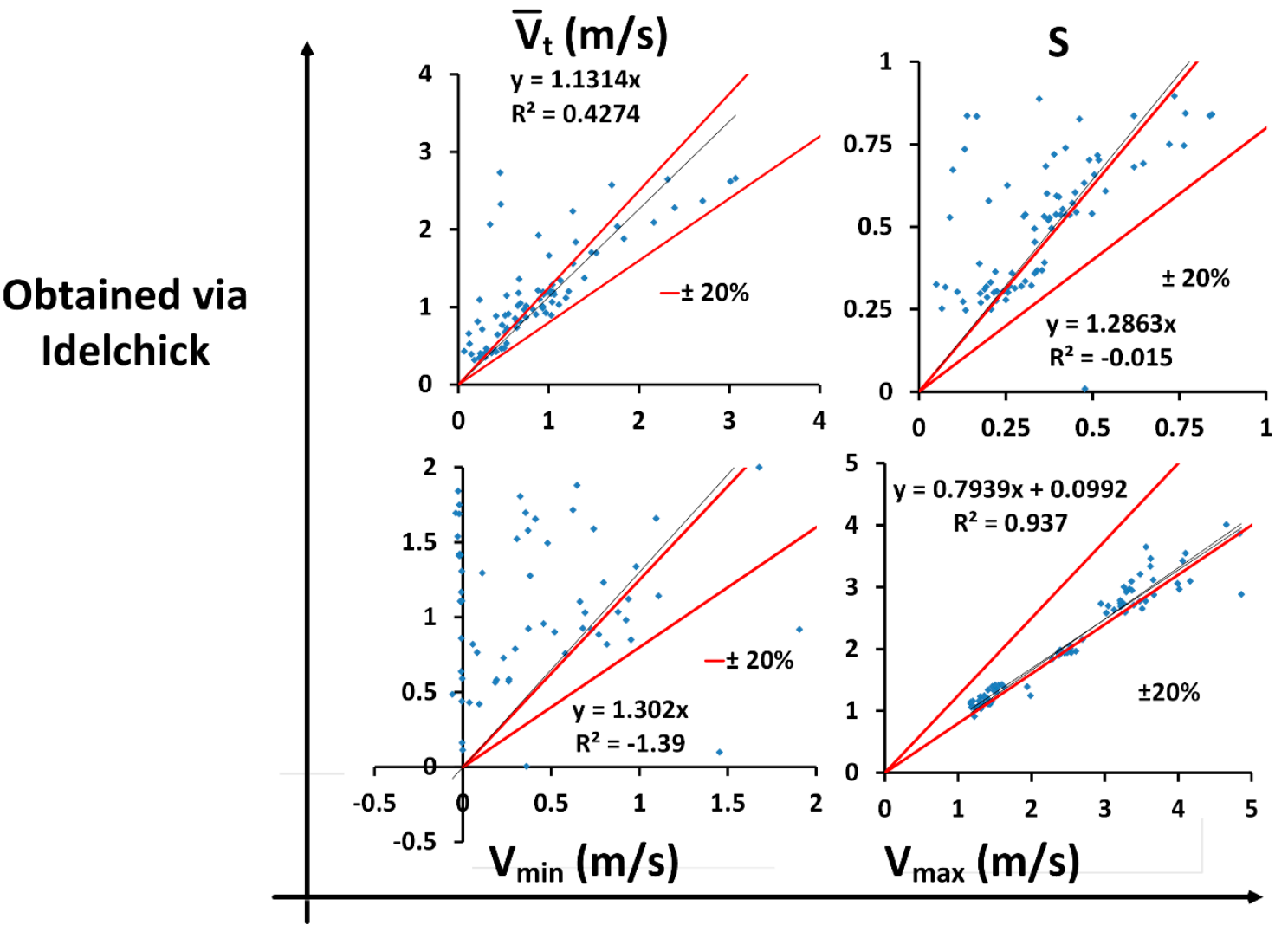

\section{Obtained via the detailed models}

Figure 9. Flow magnitudes for the outlet cross-section of the domain obtained via Idelchick vs. the flow magnitudes obtained via the detailed models.

\subsection{Application of the Compact Model with a Random Case}

In order to check the correct working of the compact model and that the correlations are able to supply coefficients that approximate the flow pattern correctly, a simulation of a new detailed model case was performed. The modeling strategy is the same as that 
presented in Bengoechea et al. [17]. The geometric and operation parameters corresponding to this new case are presented in Table 6 . Figure 10 presents the results obtained by the compact model (employing the pressure loss coefficients given by the correlations), by the detailed model, and by the coefficients provided by the Idelchick handbook [20]. As the figure shows, the prediction given by the compact model is closer to the detailed one than the prediction using the Idelchick handbook. The fit for the minimum and maximum axial velocities is better with the compact model that is introduced in this work, as is the adjustment for the tangential velocity. As the Idelchick handbook does not include pressure loss coefficients perpendicular to the flow direction, more tangential flow passes the screen when solving the flow by the coefficients given in this handbook. Therefore, the compact model presented in this work that consists of three directional pressure loss coefficients logically approximates a three-dimensional flow better.

It is necessary to note that the new case is supposed to be between those cases for which the Idelchick handbook is expected to provide a solution, as the level of the porosity of the screen is fixed to its higher value (see Table 6). This way, the value for the coefficient perpendicular to the flow direction tends towards a lower value. Therefore, through this new case, apart from showing that the compact model functions well, it was demonstrated that even for cases with high porosity, these correlations work better than the modeling currently employed.

\section{Axial velocities}

2.65

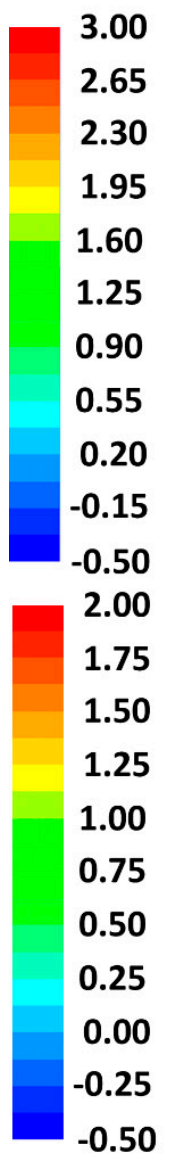

2.30

1.95

1.60

1.25

0.90

0.55

0.20

$-0.15$

$-0.50$

2.00

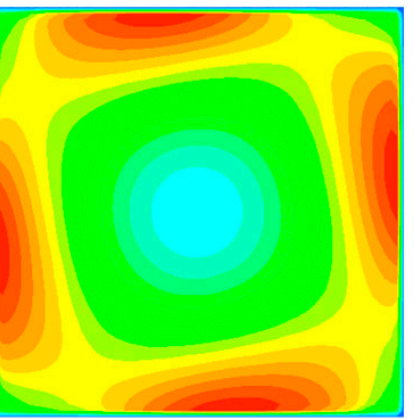

Compact model

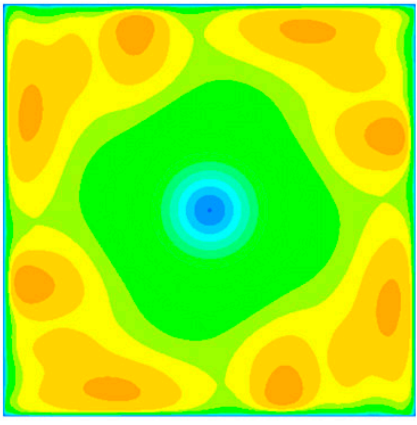

Detailed model

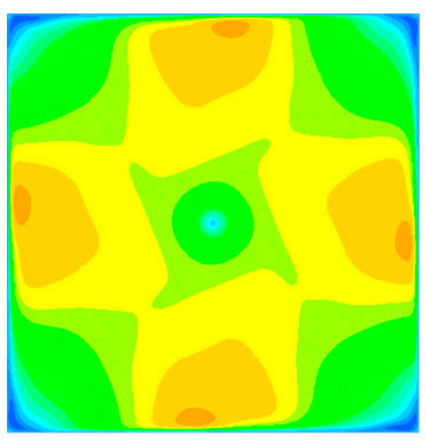

Tangential velocities

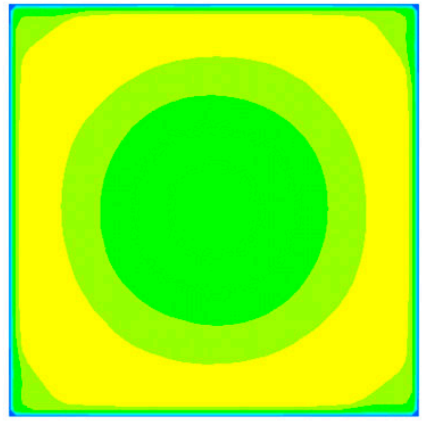

Idelchick

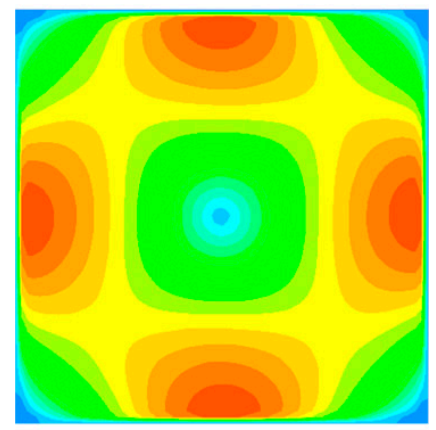
列

Figure 10. Axial and tangential velocity fields $(\mathrm{m} / \mathrm{s})$ for the outlet cross-section of the domain for the new case obtained by the compact model, by the detailed model and by Idelchick. 
Table 6. Real and coded values for each parameter in the new case.

\begin{tabular}{ccccccccc}
\hline Parameter & $D(\mathbf{m m})$ & $D_{h} / D$ & $S$ & $a(\mathbf{m m})$ & $\varepsilon(\%)$ & $\xi(\mathbf{1} / \mathbf{m m})$ & $t(\mathbf{m m})$ & $V(\mathbf{m} / \mathbf{s})$ \\
\hline Real value & 67 & 0.42 & 0.7 & 16 & 0.75 & 0.26 & 1.4 & 1.68 \\
\hline Coded value & -0.10 & 0.13 & 0.00 & 0.10 & 1 & -0.66 & -0.11 & -0.09 \\
\hline
\end{tabular}

\section{Conclusions}

A methodology for obtaining the pressure loss coefficients per unit length that define a compact model of an EMC screen based on a porous media approach was defined for a case in which the approaching flow is a fan-induced one. In addition, correlations predicting the values of the directional pressure loss coefficients as a function of the geometric and operational parameters were introduced. It is concluded that using this compact model offers thermal designers the following advantages with respect to using a detailed model or the modeling proposed by the various handbooks on pressure loss coefficients.

One advantage is that there is a very significant reduction in the time needed to create the geometry and the mesh, as it is not necessary to generate the geometries of the pores. Between 4 and $24 \mathrm{~h}$ is needed to create a detailed model, while no more than $10 \mathrm{~min}$ (less than $4 \%$ of the initial time) is required to create the compact model.

A second advantage is that as a consequence of the decrease in the number of elements that the mesh has, the time needed to converge the simulations is drastically reduced. For a detailed model, depending on the geometry, anywhere between $5 \mathrm{~h}$ and several weeks is needed to achieve a good level of convergence, whereas with a compact model, thermal designers have a reliable approximation of the flow pattern in $5 \mathrm{~min}$ (less than $1.7 \%$ of the initial time).

Therefore, the compact model presented in this work provides a quick and reliable approximation of the flow pattern that is superior to the approximations obtained by the modeling proposed in various handbooks. This approach permits electronic components to be placed into the 3D domain in such a way that a good prediction of the flow close to each component will be obtained quickly.

Author Contributions: Conceptualization, A.B. and R.A.; methodology, R.A.; software, A.B. and G.S.L.; validation, R.A., A.R. and J.C.R.; formal analysis, R.A., A.R. and J.C.R.; investigation, A.B. and R.A.; resources, R.A.; data curation, A.B.; writing-original draft preparation, A.B.; writing-review and editing, A.B., G.S.L., R.A., A.R. and J.C.R.; visualization, A.B., G.S.L., R.A., A.R. and J.C.R.; supervision, R.A.; project administration, R.A.; funding acquisition, R.A. All authors have read and agreed to the published version of the manuscript.

Funding: This research was funded by Eusko Jaurlaritza-Gobierno Vasco, Spain through Proyecto PI2011-30.

Institutional Review Board Statement: Not applicable.

Informed Consent Statement: Not applicable.

Data Availability Statement: Not applicable.

Acknowledgments: This research was funded by Eusko Jaurlaritza-Gobierno Vasco, Spain through Proyecto PI2011-30. The support of Cátedra Fundación Antonio Aranzábal-Universidad de Navarra is also gratefully acknowledged.

Conflicts of Interest: The authors declare no conflict of interest. 


\begin{tabular}{l} 
Nomenclature \\
$a$ \\
$A$ \\
$D$ \\
$D_{h}$ \\
$k$ \\
$L_{c}$ \\
$P$ \\
$S$ \\
$t$ \\
$U_{i, j}$ \\
$v$ \\
$\overline{v_{t}}$ \\
$V$ \\
$V_{a}$ \\
$V_{t}$ \\
Greek symbols \\
$\beta$ \\
$\varepsilon$ \\
$\varepsilon$ \\
$\varphi$ \\
$\mu$ \\
$\mu_{t}$ \\
$\rho$ \\
$\xi$ \\
\hline
\end{tabular}

distance between the fan and the EMC screen $(\mathrm{mm})$

area $\left(\mathrm{m}^{2}\right)$

diameter of the fan and size of the channel $(\mathrm{mm})$

hub diameter ( $\mathrm{mm}$ )

turbulent kinetic energy $\left(\mathrm{m}^{2} / \mathrm{s}^{2}\right)$

characteristic length $(\mathrm{m})$

pressure $\left(\mathrm{N} / \mathrm{m}^{2}\right)$

Swirl number (-)

thickness of the screen $(\mathrm{mm})$

velocity components $(\mathrm{m} / \mathrm{s})$

$\operatorname{velocity}(\mathrm{m} / \mathrm{s})$

area weighted average of the tangential velocity $(\mathrm{m} / \mathrm{s})$

mean axial velocity $(\mathrm{m} / \mathrm{s})$

local axial velocity $(\mathrm{m} / \mathrm{s})$

mean tangential velocity $(\mathrm{m} / \mathrm{s})$

regression coefficient (-)

porosity of the screen (\%)

rate of dissipation of the turbulent kinetic energy $\left(\mathrm{m}^{2} / \mathrm{s}^{3}\right)$

directional pressure loss coefficient (-)

dynamic viscosity $\left(\mathrm{N} \cdot \mathrm{s} / \mathrm{m}^{2}\right)$

turbulent viscosity $\left(\mathrm{N} \cdot \mathrm{s} / \mathrm{m}^{2}\right)$

density $\left(\mathrm{kg} / \mathrm{m}^{3}\right)$

ratio of perimeter to area of the pores of the screen $(1 / \mathrm{mm})$

\section{References}

1. Sharma, C.S.; Tiwari, M.K.; Zimmermann, S.; Brunschwiler, T.; Schlottig, G.; Michel, B.; Poulikakos, D. Energy efficient hotspottargeted embedded liquid cooling of electronics. Appl. Energy 2015, 138, 414-422. [CrossRef]

2. Birbarah, P.; Gebrael, T.; Foulkes, T.; Stillwell, A.; Moore, A.; Pilawa-Podgurski, R.; Miljkovic, N. Water immersion cooling of high power density electronics. Int. J. Heat Mass Transf. 2020, 147, 118918. [CrossRef]

3. Liu, Y.; Han, X.; Shen, C.; Yao, F.; Zhang, M. Experimental Study on the Evaporation and Condensation Heat Transfer Characteristics of a Vapor Chamber. Energies 2018, 12, 11. [CrossRef]

4. Estes, K.A.; Mudawar, I. Comparison of Two-Phase Electronic Cooling Using Free Jets and Sprays. J. Electron. Packag. 1995, 117, 323-332. [CrossRef]

5. Carneiro, M.V.P.; De Oliveira, P.A.; Barbosa, J.R. A compact refrigeration system based on multijet sprays for electronics thermal management. Exp. Therm. Fluid Sci. 2018, 97, 180-191. [CrossRef]

6. Hill, B.; Hill, C. Effects of Electronic Enclosure Layout on Fan Performance. In Proceedings of the ASME Winter Annual Meeting, Dallas, TX, USA, 25-30 November 1990. 90-WA/EEP-6.

7. Grimes, R.; Davies, M.; Punch, J.; Dalton, T.; Cole, R. Modeling Electronic Cooling Axial Fan Flows. J. Electron. Packag. 2000, 123, 112-119. [CrossRef]

8. Lin, S.C.; Chou, C.A. Blockage effect of axial-flow fans applied on heat sink assembly. Appl. Therm. Eng. 2004, 24, 2375-2389. [CrossRef]

9. Swim, W.B. An Experimental Study of the Effects of Inlet Plenum Walls on Axial Fan Performance. ASHRAE Trans. 2005, 111, $993-999$.

10. Baniasadi, E.; Aydin, M.; Dincer, I.; Naterer, G. Computational Aerodynamic Study of Automotive Cooling Fan in Blocked Conditions. Eng. Appl. Comput. Fluid Mech. 2013, 7, 66-73. [CrossRef]

11. Antón, R.; Bengoechea, A.; Rivas, A.; Ramos, J.C.; Larraona, G.S. Performance of Axial Fans in Close Proximity to the Electromagnetic Compatibility Screens. J. Electron. Packag. 2012, 134, 011004. [CrossRef]

12. Tanner, P.; Gorman, J.; Sparrow, E. Flow-pressure drop characteristics of perforated plates. Int. J. Numer. Methods Heat Fluid Flow 2019, 29, 4310-4333. [CrossRef]

13. Miguel, A.F. Characterization of Fluid Flow through Perforated Plates. J. Porous Media 2019, 22, 1439-1448. [CrossRef]

14. Bejan, A.; Kim, S.J.; Morega Al, M.; Lee, S.W. Cooling of stacks of plates shielded by porous screens. Int. J. Heat Fluid Flow 1995, 16, 16-24. [CrossRef]

15. Brundrett, E. Prediction of Pressure Drop for Incompressible Flow Through Screens. J. Fluids Eng. 1993, 115, 239-242. [CrossRef]

16. Bengoechea, A.; Antón, R.; Larraona, G.S.; Rivas, A.; Ramos, J.C.; Masip, Y. PIV measurements and a CFD benchmark study of a screen under fan-induced swirl conditions. Int. J. Heat Fluid Flow 2014, 46, 43-60. [CrossRef] 
17. Bengoechea; Anton, R.; Larraona, G.; Ramos, J.C.; Rivas, A. Influence of Geometrical Parameters in The Downstream Flow of A Screen Under Fan-Induced Swirl Conditions. Eng. Appl. Comput. Fluid Mech. 2014, 8, 623-638. [CrossRef]

18. Preece, D.A.; Montgomery, D.C. Design and Analysis of Experiments. Int. Stat. Rev. 1978, 46, 120. [CrossRef]

19. Baelmans, M.; Meyers, J.M.; Nevelsteen, K. Flow modeling in air-cooled electronic enclosures. In Proceedings of the Nineteenth Annual IEEE Semiconductor Thermal Measurement and Management Symposium, San Jose, CA, USA, 11-13 March 2003. [CrossRef]

20. Idelchik, I.E. Handbook of Hydraulic Resistance; Jaico Publishing House: Munbai, India, 2003.

21. Kordyban, T. Fan Swirl and Planar Resistances Don't mix. In Proceedings of the 9th International Flotherm User Conference, Orlando, FL, USA, 18-19 October 2000.

22. Anton, R.; Jonsson, H.; Moshfegh, B. Detailed CFD modeling of EMC screen for radio base stations: A benchmark study. IEEE Trans. Compon. Packag. Technol. 2007, 30, 754-763. [CrossRef]

23. Antón, R.; Jonsson, H.; Moshfegh, B. Compact CFD modelling of EMC screen for radio base stations: A porous media approach and a correlation for the directional loss coefficients. IEEE Trans. Compon. Packag. Technol. 2007, 30, 875-885. [CrossRef]

24. Antón, R.; Jonsson, H.; Moshfegh, B. Detailed CFD modelling of EMC screen for radio base stations: A conjugate heat trans-fer problem. Int. J. Heat Exch. 2007, 8, 95-116.

25. Anton, R.; Jonsson, H.; Moshfegh, B. Detailed CFD Modelling of EMC Screens for Radio Base Stations: A Parametric Study. IEEE Trans. Compon. Packag. Technol. 2009, 32, 145-155. [CrossRef]

26. Nevelsteen, K.; De Troch, K.; Mesbah, M.; Nelemans, W.; Baelmans, M. Screen characterization under fan induced swirl conditions. IEEE Trans. Components Packag. Technol. 2006, 29, 385-394. [CrossRef]

27. Najam, F.; Yu, Y.S. Compact Model for L-Shaped Tunnel Field-Effect Transistor Including the 2D Region. Appl. Sci. 2019, 9, 3716. [CrossRef]

28. Li, S.; Nezami, M.S.; Rolston, D.; Liboiron-Ladouceur, O. A Compact High-Efficient Equivalent Circuit Model of Mul-ti-QuantumWell Vertical-Cavity Surface-Emitting Lasers for High-Speed Interconnects. Appl. Sci. 2020, 10, 3865. [CrossRef]

29. Colangelo, A.; Guelpa, E.; Lanzini, A.; Mancò, G.; Verda, V. Compact Model of Latent Heat Thermal Storage for Its Integra-tion in Multi-Energy Systems. Appl. Sci. 2020, 10, 8970. [CrossRef]

30. Beér, J.; Chigier, N. Combustion Aerodynamics; Robert, E., Ed.; Krieger Publishing Company Inc.: Malabar, FL, USA, 1983.

31. Launder, B.E.; Spalding, D.B. Lectures in Mathematical Models of Turbulence; Academic Press: London, UK, 1972.

32. Launder, B.; Spalding, D. The numerical computation of turbulent flows. Comput. Methods Appl. Mech. Eng. 1974, 3, 269-289. [CrossRef]

33. $\quad$ ANSYS FLUENT ${ }^{\circledR}$ 13. In Documentation; Ansys, Inc.: Canonsburg, PA, USA, 2013.

34. Best Practice Guidelines. European Research Community on Flow, Turbulence and Combustion, Version 1.0; Best Practice Guidelines: Bushey, UK, 2000. 